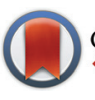

CrossMark \& click for updates

Cite this: Polym. Chem., 2016, 7, 6834

Received 18th September 2016, Accepted 18th October 2016

DOI: 10.1039/c6py01639a

www.rsc.org/polymers

\section{Sol-gel reversible metallo-supramolecular hydrogels based on a thermoresponsive double hydrophilic block copolymer $\uparrow$}

\author{
Maël Le Bohec, Manon Banère, Sandie Piogé,* Sagrario Pascual, Lazhar Benyahia \\ and Laurent Fontaine*
}

\begin{abstract}
A well-defined poly( $N, N$-dimethylacrylamide)-b-poly( $N$-isopropylacrylamide-co-2-vinyl-4,4-dimethylazlactone) thermoresponsive double hydrophilic block copolymer bearing a terpyridine entity (TpyPDMA-b-P(NIPAM-co-VDM)) was synthesized by successive RAFT polymerizations. An amphiphilic macro-chain transfer agent bearing a terpyridine moiety (Tpy-PDMA-CTA) was synthesized and used for the preparation of a double hydrophilic block copolymer (Tpy-PDMA-b-P(NIPAM-co-VDM)) by RAFT dispersion polymerization. The RAFT dispersion polymerization of water-soluble monomers showed good control over the molar mass and dispersity, as characterized by size exclusion chromatography (SEC) and ${ }^{1} \mathrm{H}-\mathrm{NMR}$ spectroscopy. Complexation in the presence of metal ions $\left(\mathrm{Fe}^{2+}\right)$ and self-assembly of the TpyPDMA-b-P(NIPAM-co-VDM) copolymer in diluted solution $(0.5 \% \mathrm{w} / \mathrm{v})$ were investigated. The formation of dynamic metallo-supramolecular flower-like micelles was demonstrated by UV-Vis spectrophotometry and dynamic light scattering (DLS). The effect of the addition of $\mathrm{Fe}^{2+}$ ions to a concentrated solution $(8 \% \mathrm{w} / \mathrm{v})$ of the Tpy-PDMA-b-P(NIPAM-CO-VDM) copolymer at low temperature was investigated and the thermal profile of the metallic bis-terpyridine complex ([Fe(Tpy-PDMA- $\left.b-P(N I P A M-C O-V D M))_{2}\right]^{2+}$ ) has been studied by differential scanning calorimetry (DSC). The influence of temperature on the aqueous solution $(8 \% \mathrm{w} / \mathrm{v})$ of the ([Fe(Tpy-PDMA-b-P(NIPAM-CO-VDM $\left.\left.))_{2}\right]^{2+}\right)$ metallic complex was investigated by rotational rheometry. The results show that the self-assembly of the thermoresponsive block of the metallic bis-terpyridine complex formed a dynamic hydrogel with a sol-gel thermoreversible transition.
\end{abstract}

\section{Introduction}

Supramolecular polymer networks, where cross-links are formed by metal coordination have received particular attention because of their intrinsic self-healing ability ${ }^{1-3}$ and the possibility of imparting the physico-chemical properties of the metal ions (optical, ${ }^{4-7}$ electrical, ${ }^{8-10}$ magnetic $^{11,12}$ or catalytic $^{13}$ ) to the resulting materials. Several strategies have been successfully applied in the design of metallo-supramolecular polymer networks, which have been classified into two distinct categories depending on the way cross-links are formed within the supramolecular network. ${ }^{14}$ The first category involves the combination of ditopic ligands and metal ions that can accommodate more than two ligands. ${ }^{15-17}$ The second strategy

Institut des Molécules et Matériaux du Mans (IMMM), UMR CNRS 6283, Université du Maine, Avenue Olivier Messiaen, 72085 Le Mans Cedex 9, France. E-mail: sandie.pioge@univ-lemans.fr, laurent.fontaine@univ-lemans.fr; Fax: +33 (o)243 8337 54; Tel: +33 (0)243833330

$\dagger$ Electronic supplementary information (ESI) available. See DOI: 10.1039/ с6ру01639a involves the combination of multitopic ligands and metal ions, leading to bis-complexes. ${ }^{18-20}$ Among multitopic polymeric ligands, block copolymer micelles bearing ligands at the surface constitute a powerful approach to tune the rheological properties and responsiveness of soft materials. ${ }^{3,21-28}$ In this case, metallo-supramolecular micellar networks are obtained by a two-step process: (1) the self-assembly of block copolymers followed by (2) metal-ligand interactions. The first step corresponding to the self-assembly is achieved by dissolution of a block copolymer in a selective solvent of one block, leading to micelles bearing ligands at the surface. The second step consists of the addition of metal ions leading to micellar gels in the concentrated regime. When stimuli-responsive (thermo- or pH-sensitive) block copolymers are used in the first step, the addition of metal ions leads to smart metallosupramolecular networks where the viscoelastic properties are controlled by the stimulus. Gohy's group developed this second strategy to trigger metallo-supramolecular polymer networks based on copolymeric micelles. ${ }^{3,21-27}$ Their studies involved a diblock copolymer based on polystyrene and poly (tert-butylacrylate) bearing a terpyridine ligand (Tpy) moiety at 
the chain-end (PS- $b$-PtBA-Tpy) which, in the presence of metal ions, yielded flower-like micelles and micellar gels in diluted and concentrated solvents, respectively. ${ }^{3,21,22}$ Then, Piogé et al. investigated stimuli-responsive metallo-supramolecular micelles starting from terpyridine-functionalized diblock copolymers based on PS and poly( $N$-isopropylacrylamide) (PS- $b$ PNIPAM-Tpy). ${ }^{29}$ In diluted aqueous medium and in the presence of metal ions, these thermoresponsive copolymers formed flower-like micelles composed of a PS core and a thermoresponsive PNIPAM shell. Such PS- $b$-PNIPAM-Tpy copolymers have then been studied by Brassinne et al. in a concentrated regime in order to obtain metallo-supramolecular hydrogels based on micelles having a thermoresponsive shell. ${ }^{25-27}$ Recently, Gohy's group elaborated a multi-sensitive micellar hydrogel using a triblock copolymer (PS- $b$-PNIPAM$b$-PDMAEMA-Tpy) including a pH-responsive poly(2-(dimethylamino)ethyl methacrylate) (PDMAEMA) block. ${ }^{23}$ All the reported studies ${ }^{3,21,22,25-27,29}$ focused on micelles containing a PS core. Such a solvophobic polymer is known to form frozen micelles. $^{30-32}$ However, dynamic micellar gels with a fast exchange rate are formed when the solvophobic block is very short $^{33-35}$ or not strongly solvophobic. ${ }^{36-38}$

In contrast with those previous studies, our contribution relies on a single copolymer paving the way for an unprecedented platform able to switch between a dynamical transient network and frozen hydrogels without varying the chemical nature or the length of the blocks. This copolymer is a double hydrophilic block copolymer based on a soluble poly ( $N, N$-dimethylacrylamide) (PDMA) block bearing terpyridine units and a thermoresponsive poly( $N$-isopropylacrylamide)co-poly(2-vinyl-4,4-dimethylazlactone) $\mathrm{P}(\mathrm{NIPAM}-$-co-VDM) statistical block. We chose PNIPAM as the thermoresponsive polymer, characterized by a LCST around $32{ }^{\circ} \mathrm{C}$. The LCST of PNIPAM can be tuned by controlling the molecular structure and composition as demonstrated by varying the molar masses, end-groups, and architectures, as well as by incorporating hydrophobic units within the PNIPAM block. ${ }^{39-42}$ Among hydrophobic units, the incorporation of amine-reactive VDM units allows for tuning the LCST of the resulting copolymer from 19 to $41{ }^{\circ} \mathrm{C} .{ }^{43}$ Moreover, the VDM units provide reactive sites for subsequent crosslinking of the micelle core to target frozen micelles. ${ }^{44}$ As well-defined terpyridine-functionalized PDMA- $b$-P(NIPAM-co-VDM) block copolymers are targeted in this study, reversible addition-fragmentation chain transfer (RAFT) polymerization was selected as the reversibledeactivation radical polymerization (RDRP) method. RAFT polymerization is one of the versatile RDRP processes as it is applicable to a wide range of monomers and it is highly tolerant to chemical functionalities. ${ }^{45,46}$

Herein, we report for the first time the synthesis of a thermoresponsive terpyridine-functionalized double hydrophilic block copolymer (Tpy-PDMA- $b$-P(NIPAM-co-VDM)) by RAFT polymerization. The complexation of Tpy-PDMA- $b$ $\mathrm{P}\left(\mathrm{NIPAM}-\mathrm{co}\right.$-VDM) copolymers with metal ions $\left(\mathrm{Fe}^{2+}\right)$ and their self-assembly in aqueous solution by hydrogen interactions in response to heat are studied in order to obtain a smart metallo-supramolecular hydrogel based on polymeric micelles (Scheme 1). Above a given temperature and concentration, hydrogels are formed; their rheological properties are then investigated by rotational rheometry in response to temperature changes. To the best of our knowledge, the rheological behavior of a metallo-supramolecular hydrogel based on micelles possessing a thermoresponsive core has never been reported up to now.

\section{Experimental}

Materials, reagents, synthetic procedures and characterization are described in the ESI. $\dagger$

\section{Results and discussion}

To study new thermoresponsive metallo-supramolecular hydrogels based on dynamic micelles, the synthesis of a watersoluble thermoresponsive diblock copolymer Tpy-PDMA- $b$ $\mathrm{P}$ (NIPAM-co-VDM) bearing a terpyridine entity was first

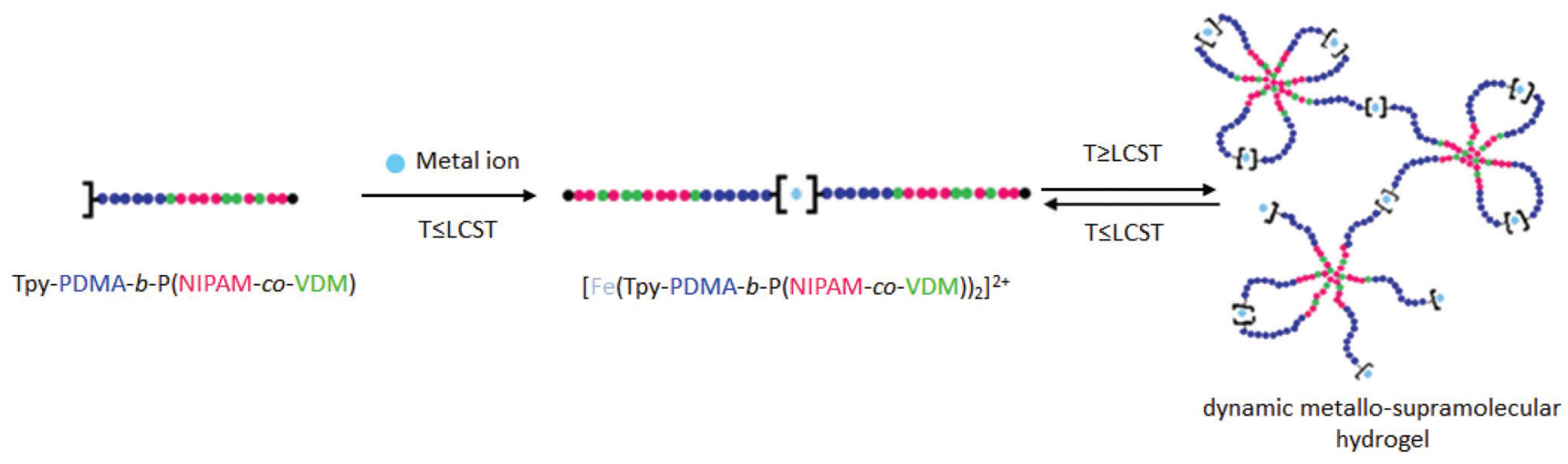

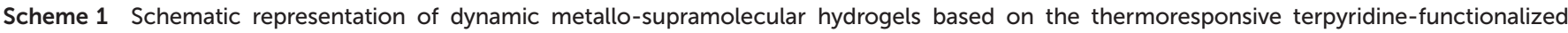
copolymer Tpy-PDMA-b-P(NIPAM-co-VDM). 

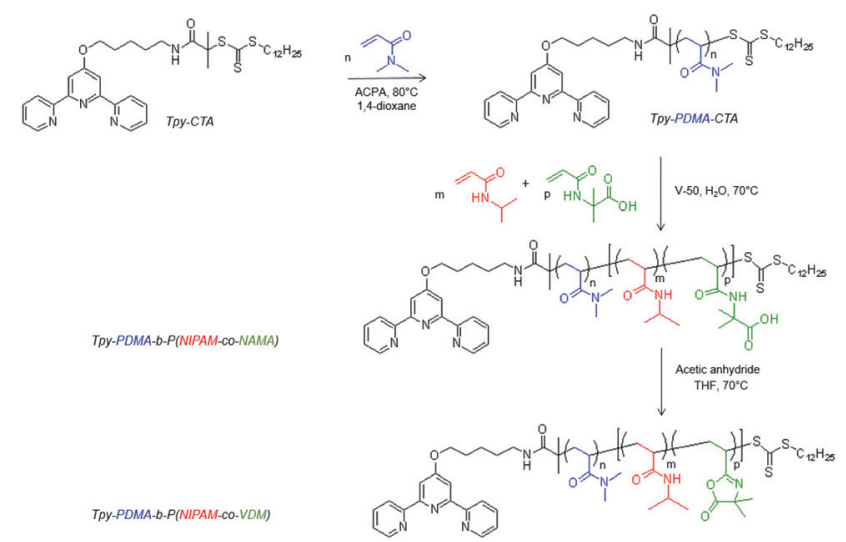

Scheme 2 Synthesis of the terpyridine functionalized thermoresponsive copolymer based on PDMA, PNIPAM and PVDM (Tpy-PDMA$b$-P(NIPAM-CO-VDM)).

considered. Such a copolymer was synthesized by successive RAFT polymerizations as depicted in Scheme 2.

\section{Synthesis and characterization of a terpyridine-functionalized poly( $N, N$-dimethylacrylamide) macromolecular chain transfer agent (TPy-PDMA-CTA)}

The polymerization of DMA was achieved in a 1,4-dioxane solvent, in the presence of Tpy-CTA as the chain transfer agent and 4,4'-azobis(4-cyanovaleric acid) (ACPA) as the initiator (Scheme 2). After 30 min, the DMA conversion for the polymerization mediated by Tpy-CTA was calculated to be $54 \%$ as determined by ${ }^{1} \mathrm{H}$ NMR spectroscopy by comparing the integrals of vinylic protons from DMA at $5.6 \mathrm{ppm}$ with the integral of $\mathrm{CHO}$ from DMF at $8 \mathrm{ppm}$ (Fig. S1 in the ESI $\dagger$ ). The PDMA number-average degree of polymerization $\left(\overline{\mathrm{DP}_{\mathrm{n}, \mathrm{PDMA}, \mathrm{NMR}}}\right)$ was determined by ${ }^{1} \mathrm{H}$ NMR spectroscopy of the precipitated polymer by comparing the intensity of the signal at $0.87 \mathrm{ppm}$ corresponding to the methyl protons at the trithiocarbonate chain-end $\left(\mathrm{CH}_{3}-\mathrm{CH}_{2}-\right.$, labeled a) with the intensity of the broad signal between 1-3.2 ppm corresponding to 9 protons of PDMA (- $\mathrm{CH}_{2}-\mathrm{CH}-\mathrm{CO}-\mathrm{N}\left(\mathrm{CH}_{3}\right)_{2}$, labeled $\left.\mathbf{b}\right)$ and to 36 protons of chain-ends $\left(-\mathrm{O}-\mathrm{CH}_{2}-\mathrm{CH}_{2}-\mathrm{CH}_{2}-\mathrm{CH}_{2}-\mathrm{CH}_{2}-\mathrm{NH}-, \quad-\mathrm{C}\left(\mathrm{CH}_{3}\right)_{2}-\right.$, $-\mathrm{S}-\left(\mathrm{CH}_{2}\right)_{11}-\mathrm{CH}_{3}$, labelled c) (Fig. S2 in the ESI $\dagger$ ). Assuming that all chains are functionalized by a trithiocarbonate, the calculated $\overline{\mathrm{DP}_{\mathrm{n}, \mathrm{PDMA}, \mathrm{NMR}}}=91$ and the number-average molar mass of the chains were determined by ${ }^{1} \mathrm{H}$ NMR spectroscopy $=9700 \mathrm{~g} \mathrm{~mol}^{-1}$. Moreover, the SEC chromatograms of TpyPDMA $_{91}$-CTA $\left(\overline{M_{\mathrm{n}, \mathrm{SEC}}}=14100 \mathrm{~g} \mathrm{~mol}^{-1}\right.$, dispersity $\left.=1.19\right)$ using RI and UV detection systems operating at $309 \mathrm{~nm}$ showed unimodal traces (Fig. 1). The presence of the trithio-moiety at the PDMA chain-end was confirmed by the presence of a peak using the $\mathrm{UV}$ detection at $309 \mathrm{~nm}$, corresponding to the $\mathrm{C}=\mathrm{S}$ bond.

The presence of the terpyridine ligand at the chain-end of Tpy-PDMA ${ }_{91}$-CTA was assessed by ${ }^{1} \mathrm{H}$ NMR spectroscopy and MALDI-TOF mass spectrometry. The ${ }^{1} \mathrm{H}$ NMR analysis shows more than $90 \%$ terpyridine functionalization by comparing the integration area of the signal at $4.21 \mathrm{ppm}$ corresponding to

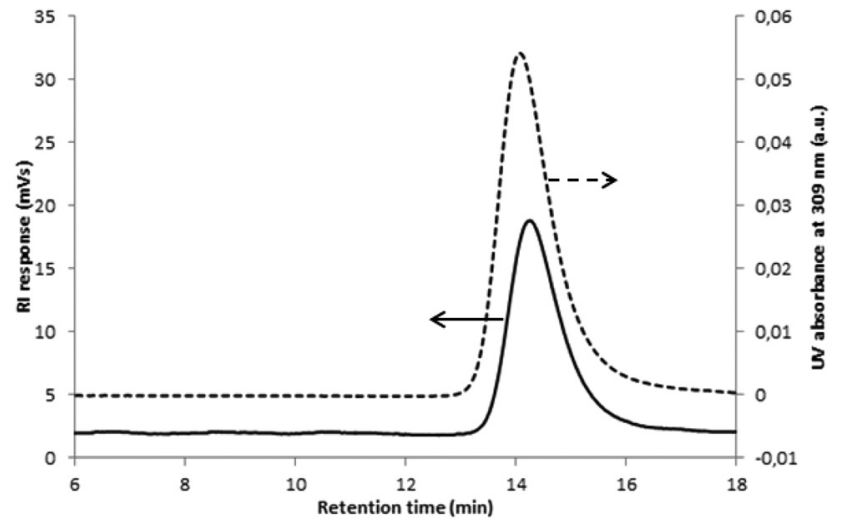

Fig. 1 Overlaid SEC chromatograms of the precipitated Tpy-PDMA ${ }_{91}$ CTA using UV detection at $309 \mathrm{~nm}(---)$ and RI detection (-).

$-{ }_{-}-\mathrm{CH}_{2}-\mathrm{CH}_{2}-$ (labeled d, Fig. S2 in the ESI $\dagger$ ) and the integration area of the signal at $0.87 \mathrm{ppm}$ of the methyl protons of the dodecyl entity $\mathrm{CH}_{3}-\mathrm{CH}_{2}$ - (labeled a, Fig. S2 in the ESI†). The MALDI-TOF mass spectrum of the resulting product (Fig. S3 in the ESI $\dagger$ ) shows a single series of peaks separated by $m / z=98.940$ corresponding to the molar mass of the DMA repeating unit (calculated value $\mathrm{m} / \mathrm{z}=99.11$ ). The peak at $\mathrm{m} / \mathrm{z}=$ 8844.411 corresponds to a polymer of 82 DMA units ionized by a sodium atom, with a terpyridine group at one chain-end and a trithiocarbonate end-group with a $\mathrm{C}_{12}$ alkyl chain at the other chain-end (calculated value $\mathrm{m} / \mathrm{z}=8844.783$ ). Both ${ }^{1} \mathrm{H}$ NMR spectroscopy and MALDI-TOF mass spectrometry analyses show the successful functionalization of PDMA with the terpyridine ligand.

As Tpy-PDMA ${ }_{91}$-CTA previously synthesized is based on a hydrophilic PDMA and a hydrophobic $\mathrm{C}_{12} \mathrm{H}_{25}$ alkyl chain, the behavior of such Tpy-PDMA ${ }_{91}$-CTA was investigated in aqueous solution at $20^{\circ} \mathrm{C}$. Hawker $e t$ al. have previously determined the critical aggregation concentration (cac) of the amphiphilic PDMA macromolecular chain transfer agent (HOOC-PDMA-CTA, $\overline{M_{\mathrm{n}, \mathrm{SEC}, \mathrm{HOOC}-\mathrm{PDMA}-\mathrm{CTA}}}=8300 \mathrm{~g} \mathrm{~mol}^{-1}$ ) by fluorescence spectroscopy to be about $0.23 \mathrm{mmol} \mathrm{L}^{-1}(0.13 \%$ $\mathrm{w} / \mathrm{v}) .{ }^{47}$ Therefore, the aqueous solution of Tpy-PDMA ${ }_{91}$-CTA at $0.5 \% \mathrm{w} / \mathrm{v}$ was analyzed by dynamic light scattering (DLS). Welldefined Tpy-PDMA ${ }_{91}$-CTA aggregates (PDi $\left.=0.08\right)$ with hydrodynamic diameters of $10 \mathrm{~nm}$ were observed. Such self-assembling behavior in aqueous solution led us to consider Tpy-PDMA ${ }_{91}$-CTA as a transurf (chain transfer agent and surfactant) in RAFT aqueous dispersion polymerization in order to obtain versatile terpyridine functionalized-polymer micelles.

\section{Synthesis of a water-soluble thermoresponsive copolymer based on PDMA, PNIPAM, and PVDM (Tpy-PDMA-b-P(NIPAM-co-VDM))}

Our strategy to obtain thermoresponsive terpyridine-functionalized copolymer micelles is based on RAFT copolymerization in dispersed media of $\mathrm{N}$-isopropylacrylamide (NIPAM) and of a water-soluble monomer, $N$-acryloyl-2-methylalanine (NAMA) as the precursor of $\mathrm{VDM}^{48}$ units (Scheme 2). The RAFT polymeri- 
zation of NAMA has never been reported in the literature. Tpy-PDMA ${ }_{91}$-CTA was used to mediate the statistical RAFT copolymerization of these two water-soluble monomers in the presence of $\mathrm{V}-50$ as the initiator, in water at $70{ }^{\circ} \mathrm{C}$ to target the Tpy-PDMA- $b$-P(NIPAM-co-NAMA) copolymer. Because NIPAM is water soluble and PNIPAM exhibits a LCST at $32{ }^{\circ} \mathrm{C}$, the initial medium was homogeneous, whereas the polymer formed a

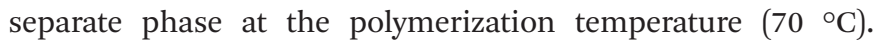
Monomer conversion was almost complete after $200 \mathrm{~min}$ of polymerization affording a stable turbid solution at $70^{\circ} \mathrm{C}$ and almost transparent solution when cooled to room temperature. Azlactone groups within the backbone were obtained by reaction of the carboxylic acid group of NAMA units with acetic anhydride at $70{ }^{\circ} \mathrm{C}$ in tetrahydrofuran (THF). The ${ }^{1} \mathrm{H}-\mathrm{NMR}$ spectrum (Fig. 2) of the resulting Tpy-PDMA ${ }_{91}-b-\mathrm{P}\left(\mathrm{NIPAM}-\mathrm{Co}^{-}\right.$ VDM) copolymer showed signals at $2.91 \mathrm{ppm}\left(-\mathrm{CO}-\mathrm{N}\left(\mathrm{CH}_{3}\right)_{2}\right.$, labeled b) characteristics of the PDMA block, a signal at $3.8 \mathrm{ppm}\left(-\mathrm{NH}-\mathrm{CH}\left(\mathrm{CH}_{3}\right)_{2}\right.$, labeled a) characteristic of PNIPAM, and at $1.4 \mathrm{ppm}\left(\mathrm{OCO}-\mathrm{C}\left(\mathrm{CH}_{3}\right)_{2}-\mathrm{N}=\right.$, labeled $\left.\mathrm{c}\right)$ characteristic of VDM units. Such signals were used to determine the molar composition of the resulting copolymers by ${ }^{1} \mathrm{H}-\mathrm{NMR}$ spectroscopy $\quad\left(\overline{\mathrm{DP}_{\mathrm{n}, \mathrm{PNIPAM}, \mathrm{NMR}}}=192, \quad \overline{\mathrm{DP}_{\mathrm{n}, \mathrm{PVDM}, \mathrm{NMR}}}=28\right.$, $\left.\overline{M_{\mathrm{n}, \mathrm{NMR}}}=35074 \mathrm{~g} \mathrm{~mol}^{-1}\right)$. The presence of the terpyridine ligand at the copolymer chain-end was also confirmed by ${ }^{1} \mathrm{H}$-NMR spectroscopy (labeled e, Fig. 2) with the presence of the aromatic proton peaks between $7.32 \mathrm{ppm}$ and $8.68 \mathrm{ppm}$.

The FT-IR spectrum of the Tpy-PDMA ${ }_{91}-b-\mathrm{P}\left(\mathrm{NIPAM}_{192}-\mathrm{co}-\right.$ $\mathrm{VDM}_{28}$ ) (Fig. $\mathrm{S} 4$ in the ESI $\dagger$ ) reveals the presence of bands at $\nu_{(\mathrm{C}=\mathrm{O})}=1818 \mathrm{~cm}^{-1}$ and $\nu_{(\mathrm{C}=\mathrm{N})}=1628 \mathrm{~cm}^{-1}$ characteristics of the azlactone ring. Furthermore, the ability to quantitatively chain-extend Tpy-PDMA-CTA to target a diblock copolymer was evidenced by clear shifts of SEC traces from higher retention times (Tpy-PDMA ${ }_{91}$-CTA) to lower retention times (Tpy-PDMA $\left.{ }_{91}-b-\mathrm{P}\left(\mathrm{NIPAM}_{192}-\mathrm{co}-\mathrm{VDM}_{28}\right)\right)$, indicating an increase in molar masses after copolymerization (Fig. 3(A)). The Tpy-PDMA ${ }_{91}$-CTA was efficiently used as a macromolecular chain transfer agent leading to well-defined block copolymers as shown by the symmetrical SEC chromatograms of the resulting copolymers $\left(\overline{M_{\mathrm{n}, \mathrm{SEC}}}=43800 \mathrm{~g} \mathrm{~mol}^{-1}\right.$, dispersity $\left.=1.42\right)$. These results demonstrate that the aqueous dispersion copolymerization is well-controlled. Moreover, the block copolymer was analyzed by SEC using an on-line diode array detector to check the UV-Vis detectable moieties (Fig. 3(B)). The presence of the attached trithiocarbonate moiety and the terpyridine group over the complete molar mass distribution is shown by SEC traces using UV-Vis detection at $309 \mathrm{~nm}$ and at $290 \mathrm{~nm}$, respectively. The formation of metallo-supramolecular copolymer micelles based on a well-defined Tpy-PDMA 9 T1 $^{-} b$ $\left(\mathrm{NIPAM}_{192}-\mathrm{Co}-\mathrm{VDM}_{28}\right)$ copolymer and $\mathrm{Fe}^{2+}$ ions, which is known to generate thermodynamically stable and redoxsensitive complexes, was then studied in diluted and concentrated regimes (Scheme 3). ${ }^{49,50}$

\section{Metallo-supramolecular copolymer micelles from metallic bis-terpyridine complexes Fe(II)-bis-PDMA-b-P(NIPAM-co-VDM) in the diluted regime}

The complexation behavior of the Tpy-PDMA ${ }_{91}-b-\left(\mathrm{NIPAM}_{192}-\mathrm{co}-\right.$ $\mathrm{VDM}_{28}$ ) with $\mathrm{Fe}^{2+}$ ions was investigated in the diluted solution

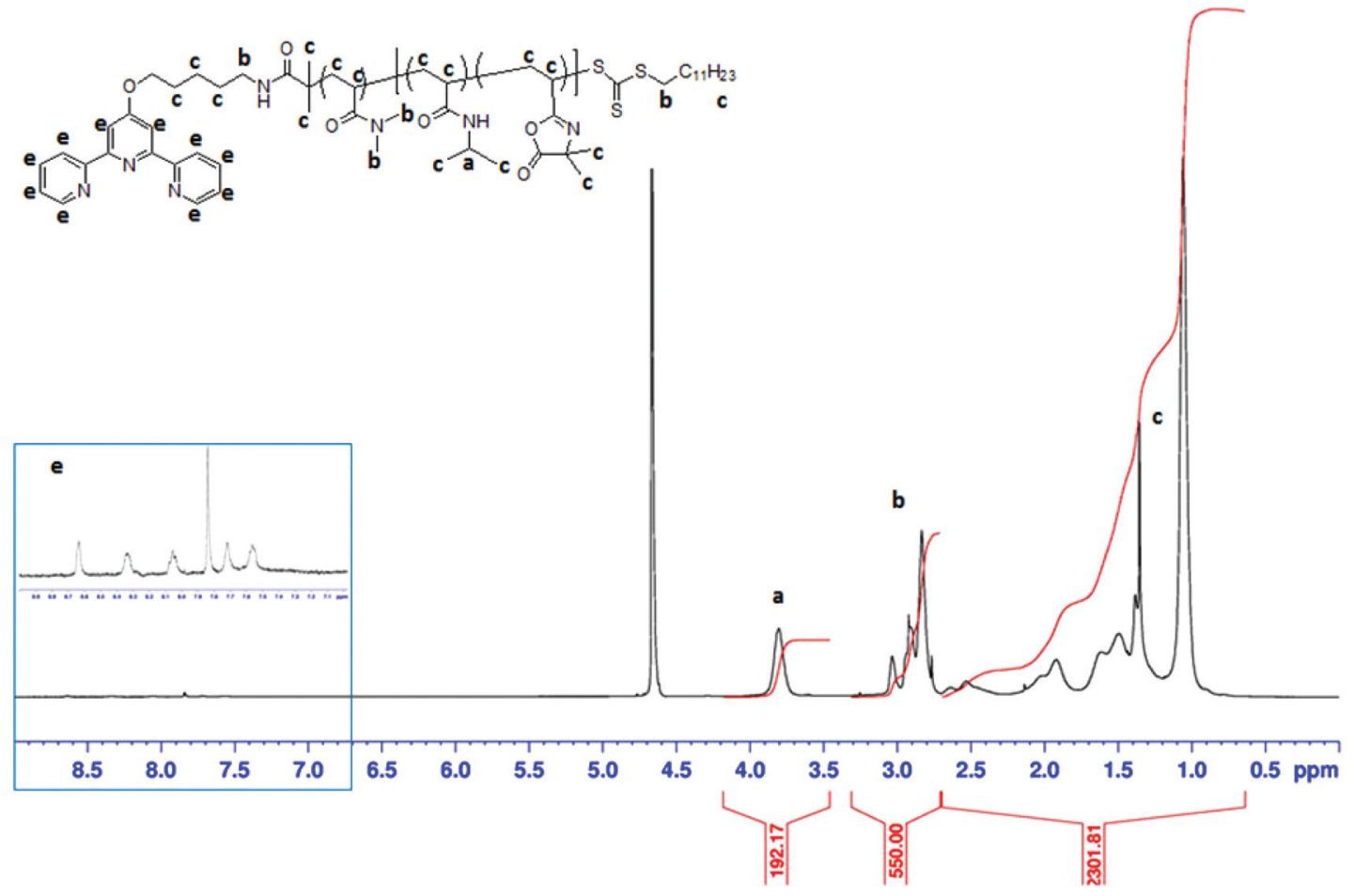

Fig. $2{ }^{1} \mathrm{H}-\mathrm{NMR}$ spectrum $\left(400 \mathrm{MHz}, \mathrm{D}_{2} \mathrm{O}\right)$ of purified Tpy-PDMA ${ }_{91}-b-\mathrm{P}\left(\mathrm{NIPAM}_{192}-\mathrm{CO}-\mathrm{VDM}_{28}\right)$. 
(A)

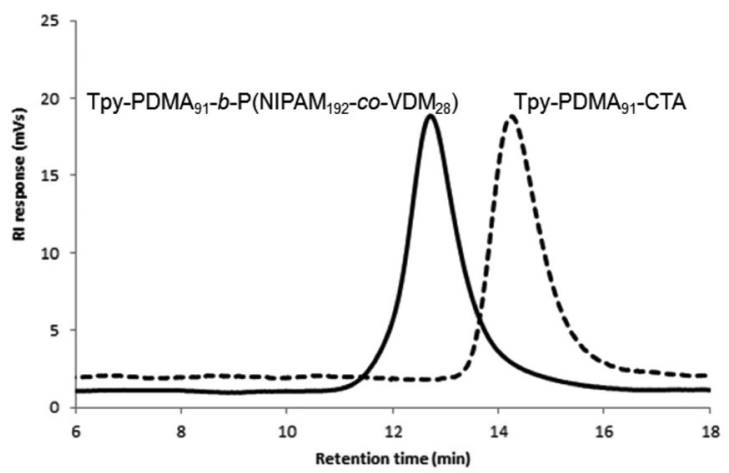

(B)

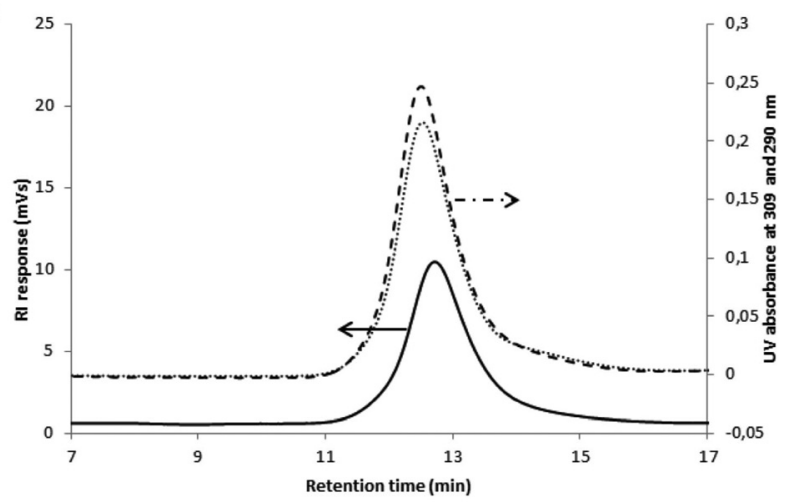

Fig. 3 (A) SEC traces of (---) Tpy-PDMA ${ }_{91}-$ CTA and (-) Tpy-PDMA $A_{91}-b-$ P(NIPAM $\left.192-C O-V_{21}\right)$ and (B) overlaid SEC traces of Tpy-PDMA ${ }_{91}-b-$ $\left.\mathrm{P}_{\left(N I P A M_{192}-{ }^{-C O}-V_{D D}\right.}\right)$ using RI (-) and UV detection at $309 \mathrm{~nm}(---)$ and $290 \mathrm{~nm}$ (...).
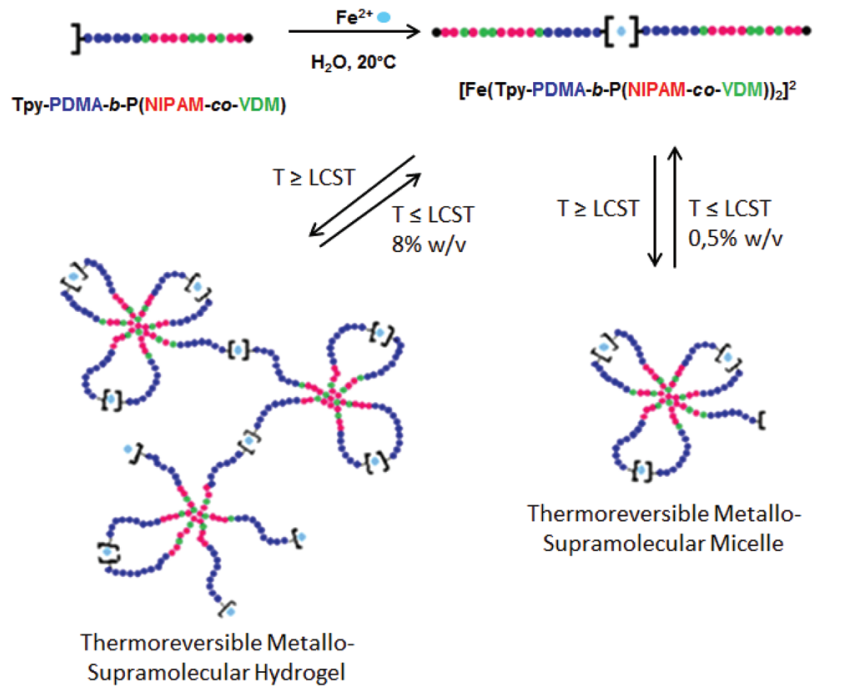

Scheme 3 Schematic representation of reversible metallo-supramolecular copolymer micelles and hydrogels elaborated from Tpy-PDMA 9 - $^{-}$ $b$-P(NIPAM $\left.192-C O-V_{28}\right)$ in the diluted $(0.5 \% \mathrm{w} / \mathrm{v})$ and concentrated regimes $(8 \% \mathrm{~W} / \mathrm{v})$, respectively.

using UV-Vis spectroscopy. The Tpy-PDMA ${ }_{91}-b$-P(NIPAM ${ }_{192}-c o-$ $\mathrm{VDM}_{28}$ ) block copolymer and the $\mathrm{Fe}^{2+}$ ions were stirred in water in a molar ratio of $2: 1$. The UV-vis spectrum revealed an

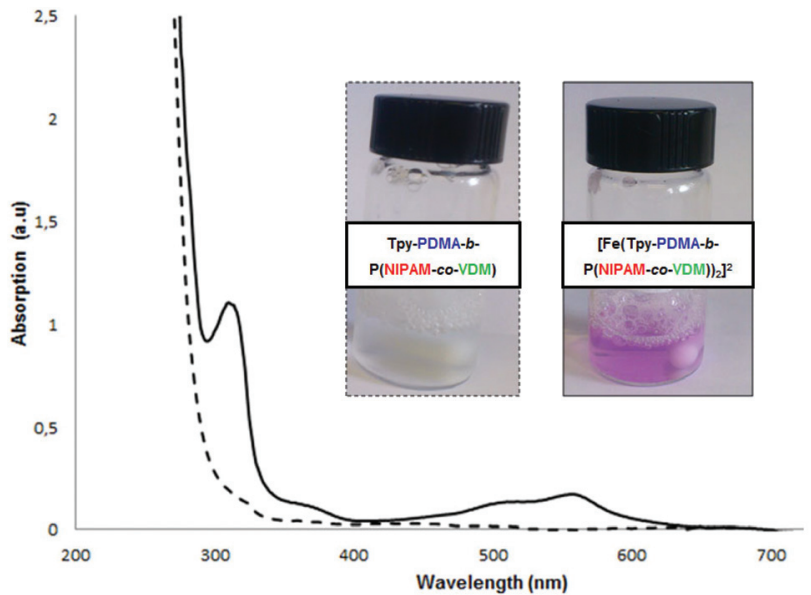

Fig. 4 UV-vis spectra and photos of (---) the uncomplexed Tpy$\mathrm{PDMA}_{91}-b-\mathrm{P}\left(\mathrm{NIPAM}_{192}-\mathrm{CO}^{\left.-V_{D} \mathrm{~V}_{28}\right)}\right.$ block copolymer and of the $(-)$ $\left[\mathrm{Fe}\left(\mathrm{Tpy}_{\mathrm{P}}-\mathrm{PDMA}_{91}-b-\mathrm{P}\left(\mathrm{NIPAM}_{192}-\mathrm{CO}-\mathrm{VDM}_{28}\right)\right)_{2}\right]^{2+}$ complex in water at $0.5 \% \mathrm{w} / \mathrm{v}$

intense absorption in the visible region, the color of the complex being intense purple (Fig. 4). A distinct metal to ligand charge transfer band (MLCT) was detected at $558 \mathrm{~nm}$ indicating that the metallic bis-terpyridine complexes [Fe(TpyPDMA- $b$-P(NIPAM- $c o$-VDM $\left.))_{2}\right]^{2+}$ were formed. ${ }^{51}$

Due to its thermoresponsive character, the metallic bisterpyridine complex $\left[\mathrm{Fe}(\text { Tpy-PDMA- } b-\mathrm{P}(\mathrm{NIPAM}-\mathrm{co}-\mathrm{VDM}))_{2}\right]^{2+}$ is capable of self-assembly in aqueous solution at temperature above the LCST to form micelles with a hydrophobic P(NIPAM$c o$-VDM) core and a hydrophilic PDMA shell bearing terpyridine units at the chain-end. This process was investigated by DLS by directly dissolving the complex into pure water $(0.5 \% \mathrm{w} / \mathrm{v})$. Particle sizes and particle size distributions calculated by CONTIN analysis were obtained at $20^{\circ} \mathrm{C}(\mathrm{T}<\mathrm{LCST})$ and $45{ }^{\circ} \mathrm{C}(\mathrm{T}>\mathrm{LCST})$ at an angle detection of $173^{\circ}$. At $20^{\circ} \mathrm{C}$, the aqueous solution of [Fe(Tpy-PDMA- $b$-P(NIPAM- $c o-$ $\left.\mathrm{VDM}))_{2}\right]^{2+}$ exhibits an average hydrodynamic diameter $\left(D_{\mathrm{h}}\right)$ of $11 \mathrm{~nm}$ characteristic of unimers (Fig. 5). When the LCST is

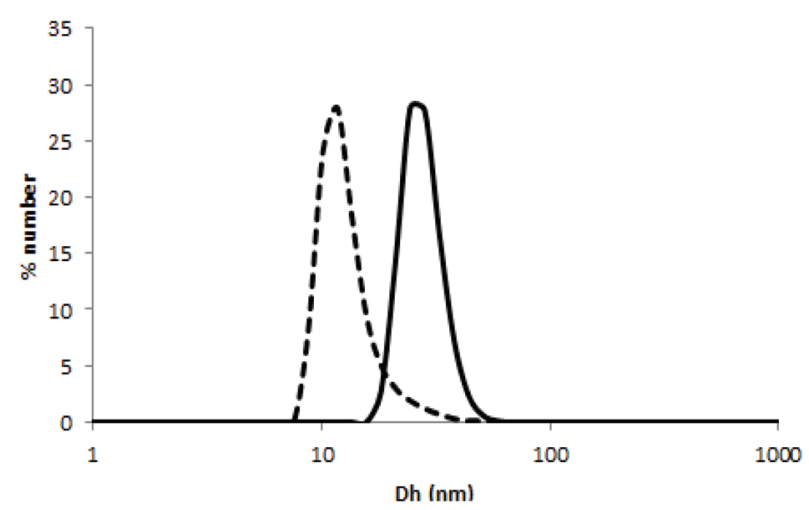

Fig. 5 Particle size distribution from dynamic light scattering of the (---) $\left[\mathrm{Fe}(\text { Tpy-PDMA-b-P(NIPAM-CO-VDM) })_{2}\right]^{2+}$ complex in water at $20^{\circ} \mathrm{C}$ and the $(-)\left[\mathrm{Fe}(\text { Tpy-PDMA- } b-\mathrm{P}(\mathrm{NIPAM}-\mathrm{CO}-\mathrm{VDM}))_{2}\right]^{2+}$ complex in water at $45^{\circ} \mathrm{C}$. 
reached, $\left[\mathrm{Fe}(\text { Tpy-PDMA- } b-\mathrm{P}(\mathrm{NIPAM}-\mathrm{co}-\mathrm{VDM}))_{2}\right]^{2+}$ self-assembles into well-defined flower-like micelles with $D_{\mathrm{h}}$ of $27 \mathrm{~nm}$ (PDi = 0.05) (Fig. 5). The self-assembly behavior of the complex is fully reversible and has been checked upon cooling. Similar results were observed for a [Fe(Tpy-PDMA- $b$-P(NIPAM-co$\left.\mathrm{VDM}) \mathrm{I}_{2}\right]^{2+}$ solution at $0.5 \% \mathrm{w} / \mathrm{v}$ obtained by dilution of the $8 \% \mathrm{w} / \mathrm{v}$ solution. These results demonstrate that the $\left[\mathrm{Fe}(\mathrm{Tpy}-\mathrm{PDM} \text { - } b \text {-P(NIPAM-co-VDM })_{2}\right]^{2+}$ complex formed thermoresponsive micelles whose organization is preparation independent.

Thermoresponsive metallo-supramolecular hydrogels from the $\mathrm{Fe}(\mathrm{II})-\mathrm{bis}-\mathrm{Tpy}-\mathrm{PDMA}_{91}-\mathrm{b}-\mathrm{P}\left(\mathrm{NIPAM}_{192}-\mathrm{co}^{-\mathrm{VDM}_{28}}\right)$ complex in the concentrated regime

The thermoresponsive character of the metallic bis-terpyridine complex [Fe(Tpy-PDMA- $b$-P(NIPAM-co-VDM $\left.)_{2}\right]^{2+}$ in the concentrated regime $(8 \% \mathrm{w} / \mathrm{v})$ was investigated through phase transition using differential scanning calorimetry (Fig. S5 in the ESI $\dagger$ ). Practically, the heat-induced phase transition of the complex is identified as an endotherm in the thermogram. ${ }^{52}$ The thermal transition of the [Fe(Tpy-PDMA- $b$-P(NIPAMco-VDM $\left.))_{2}\right]^{2+}$ complex was determined to be around $33.9{ }^{\circ} \mathrm{C}$, from the maximum of the endotherm. The phase transition of the complex is fully reversible and has been checked upon cooling. The transition temperature upon cooling was however $1.3^{\circ} \mathrm{C}$ lower than that in the heating process, clearly indicating a hysteresis, as usually observed for PNIPAM. ${ }^{53}$ It has to be noted that hydrophilic charged terpyridine complex (with $\mathrm{Cl}^{-}$ counter ions), known to greatly increase the LCST of PNIPAM, ${ }^{54}$ has no significant impact in the case of this system where the charged terpyridine complex is connected to the hydrophilic PDMA block and not directly to the P(NIPAMco-VDM) block.

Aqueous solutions of Tpy-PDMA ${ }_{91}-b-\mathrm{P}\left(\mathrm{NIPAM}_{192}-c o-\mathrm{VDM}_{28}\right)$ block copolymers at different concentrations (2 to $8 \% \mathrm{w} / \mathrm{v}$ ) containing half a molar equivalent of $\mathrm{Fe}^{2+}$ ions with respect to terpyridine were prepared under stirring at $20{ }^{\circ} \mathrm{C}$. In contrast with an aqueous solution containing a Tpy-PDMA $91^{-} b$ $\mathrm{P}\left(\mathrm{NIPAM}_{192}-\mathrm{co}-\mathrm{VDM}_{28}\right)$ block copolymer, an intense purple colour together with a higher viscosity was observed after addition of $\mathrm{Fe}^{2+}$ ions (Fig. 6). Such behavior could be explained by the formation of metallic bis-terpyridine complexes [Fe(Tpy$\mathrm{PDMA}_{91}-b$-(NIPAM$\left.\left.\left.{ }_{192}-\mathrm{Co}-\mathrm{VDM}_{28}\right)\right)_{2}\right]^{2+}$ only due to the presence of terpyridine entities. The increase in the (Tpy-PDMA ${ }_{91}-b-\mathrm{P}$ $\left(\mathrm{NIPAM}_{192}-\mathrm{Co}-\mathrm{VDM}_{28}\right)$ ) concentration (from $2 \% \mathrm{w} / \mathrm{v}$ to $8 \% \mathrm{w} / \mathrm{v}$ ) maintaining half a molar equivalent of $\mathrm{Fe}^{2+}$ ions leads to an increase of viscosity of the bis-terpyridine complex solutions as illustrated in (Fig. 6).

The dependence of the viscosity on the shear rate of the $\left[\mathrm{Fe}\left(\mathrm{Tpy}_{\mathrm{PDMA}} \mathrm{PD}_{91}-b-\left(\mathrm{NIPAM}_{192}-\mathrm{CO}-\mathrm{VDM}_{28}\right)\right)_{2}\right]^{2+}$ aqueous solution at $8 \% \mathrm{w} / \mathrm{v}$ was measured at $20^{\circ} \mathrm{C}$ (Fig. 7). This flow experiment showed that the system was a Newtonian fluid at a low shear rate. At an intermediate shear rate a slight shear thickening behavior was observed, followed by a shear thinning behavior for a high shear rate. This behavior is similar to the one observed with transient networks formed by two associative end-block

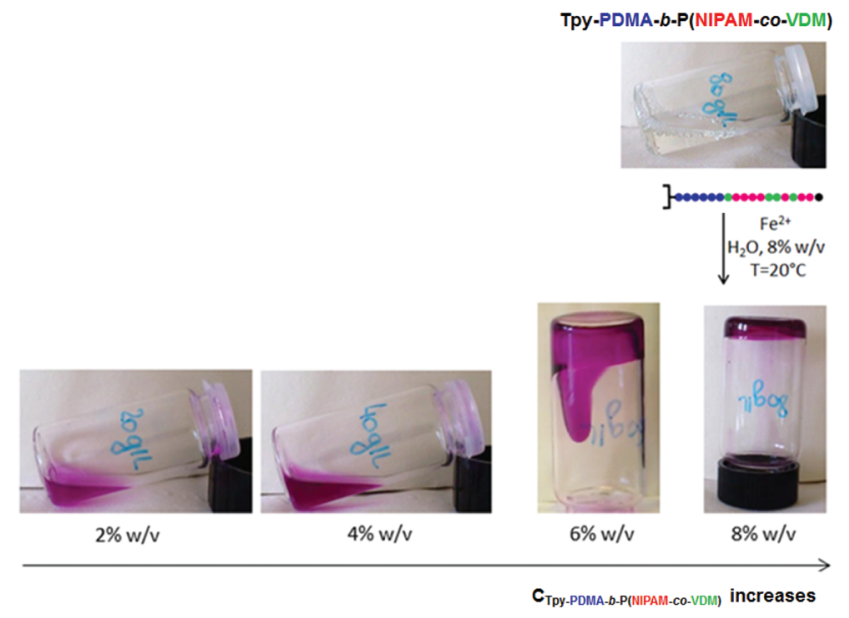

Fig. 6 Addition of Fe(II) ions to Tpy-PDMA ${ }_{91}-b-P\left(N_{I P A M} 192-C O-V D M_{28}\right)$ block copolymer solutions at different concentrations $(2$ to $8 \% \mathrm{w} / \mathrm{v}$, 0.5 molar eq. of $\mathrm{Fe}^{2+}$ ) and at $20^{\circ} \mathrm{C}$.

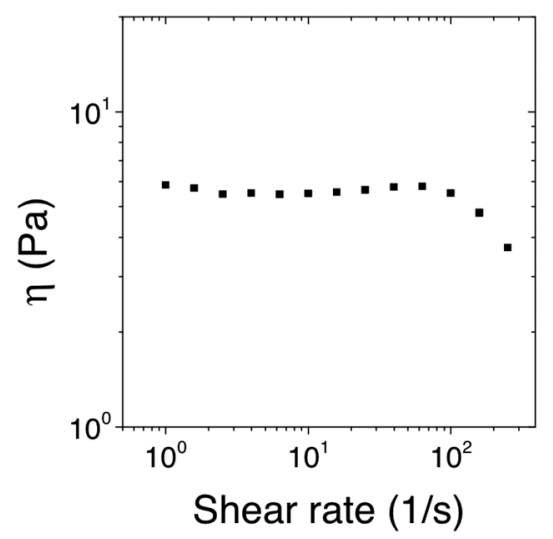

Fig. 7 Viscosity versus shear rate for the [Fe(Tpy-PDMA ${ }_{91}-b-\left(N_{1 P A M}{ }_{192}-C O-\right.$ $\left.\left.\left.\mathrm{VDM}_{28}\right)\right)_{2}\right]^{2+}$ solution $\left(0.5\right.$ molar eq. of $\mathrm{Fe}^{2+}, 8 \% \mathrm{w} / \mathrm{v}$ of the copolymer) at $20^{\circ} \mathrm{C}$.

copolymers. ${ }^{55}$ The shear-thickening is related to non-Gaussian stretching of the bridges or by the formation of more bridges. ${ }^{56}$ At higher shear rates shear-thinning is observed as more bridges are broken than being formed. The flow curve implies that bis-terpyridine complexes act as associative transient cross-linkers with a finite lifetime.

Fig. 8 shows the frequency dependence of the storage $G^{\prime}$ and loss $G^{\prime \prime}$ moduli for the [Fe(Tpy-PDMA ${ }_{91}-b-\left(\mathrm{NIPAM}_{192}-\mathrm{Co}-\right.$ $\left.\left.\left.\mathrm{VDM}_{28}\right)\right)_{2}\right]^{2+}$ aqueous solution $(8 \% \mathrm{w} / \mathrm{v})$ at $20{ }^{\circ} \mathrm{C}$. The frequency dependence measurements were done in the linear regime where there was no influence of the strain of the measured moduli. The system shows a liquid-like behavior on the frequency range where $G^{\prime \prime}$ and $G^{\prime}$ increase with $f$ and $f^{2}$ respectively. The system behaves like a Maxwell liquid as it is reported for a transient associative network with a relaxation time $\tau=$ $1 / 2 \pi f=1.6 \times 10^{-2} \mathrm{~s}$, given when $G^{\prime}$ crosses $G^{\prime \prime}$ at a frequency $f=$ $10 \mathrm{~Hz}$. At $20{ }^{\circ} \mathrm{C}$ temperature when the PNIPAM, [Fe(TpyPDMA $\left.\left._{91}-b-\left(\mathrm{NIPAM}_{192}-\mathrm{co}-\mathrm{VDM}_{28}\right)\right)_{2}\right]^{2+}$, is more hydrophilic, both 


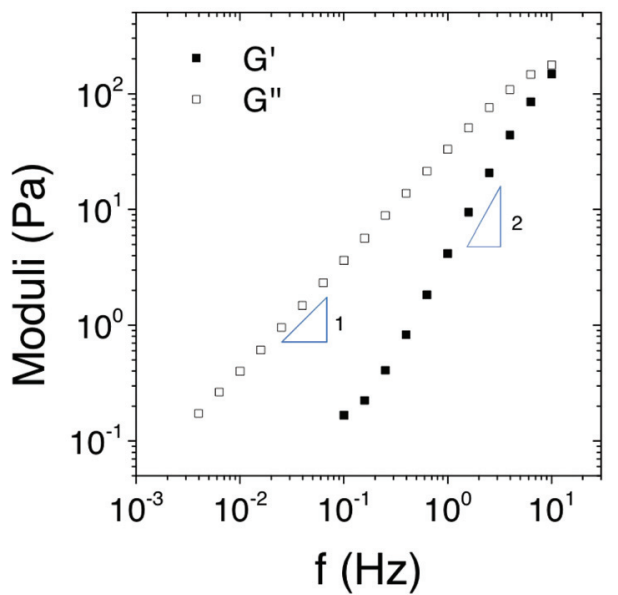

Fig. 8 Frequency dependence of the viscoelastic moduli $G^{\prime}$ and $G^{\prime \prime}$ (filled and open symbols, respectively) of the [Fe(Tpy-PDMA $A_{91}-b-$ $\left.\left.\left(\mathrm{NIPAM}_{192}-\mathrm{CO}-\mathrm{VDM}_{28}\right)\right)_{2}\right]^{2+}$ aqueous solution $\left(0.5\right.$ molar eq. of $\mathrm{Fe}^{2+}, 8 \%$ $\mathrm{w} / \mathrm{v}$ of the copolymer) at $20^{\circ} \mathrm{C}$.

flow and dynamic measurements show a transient networklike behavior where the metal complexes act as the associative end-block with a finite life time which is not necessarily the relaxation time of the transient network.

The rheological behavior of the $\left[\mathrm{Fe}\left(\mathrm{Tpy}-\mathrm{PDMA}_{91}-b-\right.\right.$ $\left.\left.\left(\mathrm{NIPAM}_{192}-\mathrm{Co}-\mathrm{VDM}_{28}\right)\right)_{2}\right]^{2+}$ aqueous solution $(8 \% \mathrm{w} / \mathrm{v})$ was also investigated during a temperature ramp of $5^{\circ} \mathrm{C} \mathrm{min}^{-1}$ between 5 and $45{ }^{\circ} \mathrm{C}$ for both heating and cooling (Fig. 9). First, one can notice that the behavior is completely reversible when the sample is returned to the initial temperature. Moreover, a hysteresis phenomenon was observed for $G^{\prime}$ and $G^{\prime \prime}$. Finally, during heating the moduli decrease uniformly up to the LCST, and then $G^{\prime \prime}$ decreases more drastically whereas $G^{\prime}$ starts to increase and become higher than $G^{\prime}$ denoting a liquid/solid transition of the $\left[\mathrm{Fe}\left(\text { Tpy-PDMA } 91-b-\left(\mathrm{NIPAM}_{192}-c o-\mathrm{VDM}_{28}\right)\right)_{2}\right]^{2+}$

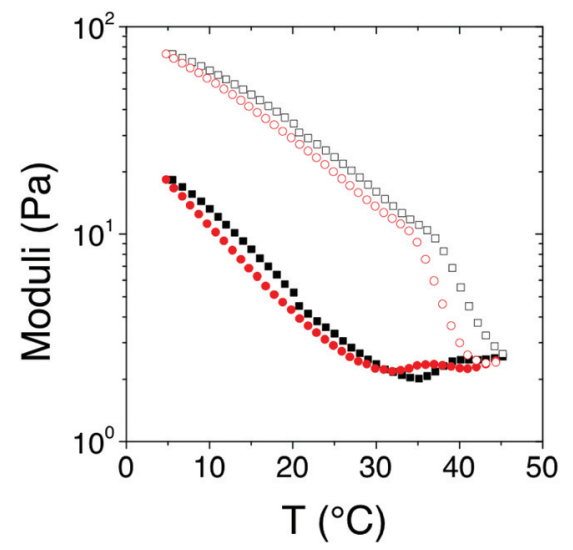

Fig. 9 Temperature dependence of the viscoelastic moduli $G^{\prime}$ and $G^{\prime \prime}$ (filled and open symbols, respectively) for heating and (square) and cooling ramps (circle) at a rate of $5{ }^{\circ} \mathrm{C} \mathrm{min}-1$ and a frequency of $1 \mathrm{~Hz}$ and a strain of $1 \%$ of the $\left[\mathrm{Fe}\left(\mathrm{Tpy}-\mathrm{PDMA}_{91}-b-\left(\mathrm{NIPAM}_{192}-\mathrm{CO}-\mathrm{VDM}_{28}\right)\right)_{2}\right]^{2+}$ aqueous solution at $8 \% \mathrm{w} / \mathrm{v}$.

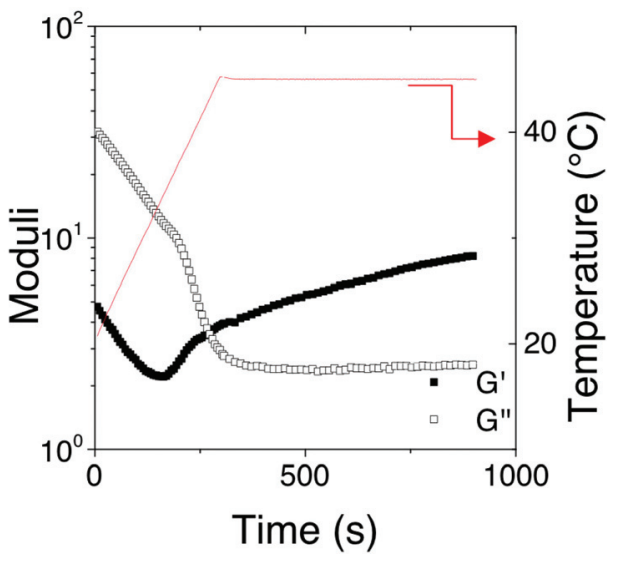

Fig. 10 Time dependence of the viscoelastic moduli $G^{\prime}$ and $G^{\prime \prime}$ (filled and open symbols, respectively) after a jump from 20 to $45^{\circ} \mathrm{C}$ at a rate of $5{ }^{\circ} \mathrm{C} \mathrm{min}^{-1}$ of the $\left[\mathrm{Fe}\left(\mathrm{Tpy}-\mathrm{PDMA}_{91}-b-\left(\mathrm{NIPAM}_{192}-\mathrm{CO}-\mathrm{VDM}_{28}\right)\right)_{2}\right]^{2+}$ aqueous solution at $8 \% \mathrm{w} / \mathrm{v}$. The frequency was set to $1 \mathrm{~Hz}$ and the strain was fixed at $1 \%$. The solid line represents the temperature.

aqueous solution when crossing the LCST. In addition, the time dependence after a jump from 20 to $45{ }^{\circ} \mathrm{C}$ shows that the steady state of the new structure is not instantaneous but takes at least $10 \mathrm{~min}$ to be stable (Fig. 10).

The frequency dependence of $G^{\prime}$ and $G^{\prime \prime}$ of the [Fe(TpyPDMA $\left.\left._{91}-b-\left(\mathrm{NIPAM}_{192}-\mathrm{co}-\mathrm{VDM}_{28}\right)\right)_{2}\right]^{2+}$ aqueous solution at a concentration of $8 \% \mathrm{w} / \mathrm{v}$ was investigated at the end of the experiment as shown in Fig. 10. Although after $10 \mathrm{~min}$ the evolution of the moduli is too slow, one can consider that the frequency dependence as shown in Fig. 11 (which took only $3 \mathrm{~min}$ ) is mainly in a stationary regime, i.e. no significant evolution of the sample behavior between the beginning and the end of the frequency sweep. The results confirm that this system behaves solid-like at $45{ }^{\circ} \mathrm{C}$ over the whole frequency range (Fig. 11) since $G^{\prime}>G^{\prime \prime}$ and the two moduli tend to a plateau at lower frequencies. At higher frequencies, it is common that some relaxation process may subsist. This is the origin of the slight

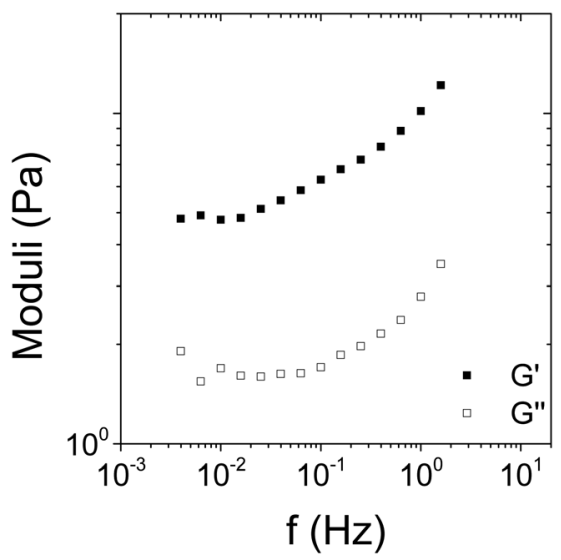

Fig. 11 Frequency dependence of the viscoelastic moduli $G^{\prime}$ and $G^{\prime \prime}$ (filled and open symbols, respectively) of the [Fe(Tpy-PDMA-b-P $\left.(\text { NIPAM-CO-VDM) })_{2}\right]^{2+}$ aqueous solution at $45^{\circ} \mathrm{C}$. 
increase of the moduli with frequency. The rheological study of this metallic bis-terpyridine complex [Fe(Tpy-PDMA ${ }_{91}-b$ $\left.\left.\left(\mathrm{NIPAM}_{192}-\mathrm{Co}-\mathrm{VDM}_{28}\right)\right)_{2}\right]^{2+}$ aqueous solution in a concentrated regime shows that this system is viscoelastic with a liquid-like behavior at temperature below LCST and tends to a solid like behavior at high temperature.

\section{Conclusions}

A well-defined thermosensitive double hydrophilic block copolymer (Tpy-PDMA- $b$-P(NIPAM-co-VDM)) bearing a terpyridine moiety at the $\alpha$-position of the chain-end was successfully prepared using RAFT sequential copolymerization in aqueous dispersed media. A metallic bis-terpyridine complex was formed by addition of $\mathrm{Fe}^{2+}$ ions to a concentrated solution of the terpyridine-functionalized double hydrophilic copolymer. Increasing the temperature of the corresponding solution causes self-assembly of the thermoresponsive block and formation of a hydrogel with a sol-gel thermoreversible transition. The introduction of azlactone units in such a double hydrophilic copolymer enables modulation of the temperature of sol-gel transition in accordance with a specific application. In addition, the azlactone units allow for further reversible core-crosslinking by reaction with a redox-sensitive diamine in order to switch between dynamic and frozen metallosupramolecular hydrogels.

\section{Acknowledgements}

We thank Amélie Durand and Corentin Jacquemmoz for NMR analyses, Emmanuelle Mebold for SEC analyses, and Emilie Choppe for NAMA synthesis.

\section{Notes and references}

1 S. Bode, L. Zedler, F. H. Schacher, B. Dietzek, M. Schmitt, J. Popp, M. D. Hager and U. S. Schubert, Adv. Mater., 2013, 25, 1634-1638.

2 S. Bode, R. K. Bose, S. Matthes, M. Ehrhardt, A. Seifert, F. H. Schacher, R. M. Paulus, S. Stumpf, B. Sandmann, J. Vitz, A. Winter, S. Hoeppener, S. J. Garcia, S. Spange, S. van der Zwaag, M. D. Hager and U. S. Schubert, Polym. Chem., 2013, 4, 4966-4973.

3 P. Guillet, C. Mugemana, F. J. Stadler, U. S. Shubert, C. A. Fustin, C. Bailly and J. F. Gohy, Soft Matter, 2009, 5, 3409-3411.

4 F. Barigelletti, L. Flamigni, V. Balzani, J. Collin, J. Sauvage, A. Sour, E. Constable and A. Thompson, J. Am. Chem. Soc., 1994, 116, 7692-7699.

5 C. Chow, S. Fujii and J. M. Lehn, Angew. Chem., Int. Ed., 2007, 46, 5007-5010.

6 M. Burnworth, L. M. Tang, J. R. Kumpfer, A. J. Duncan, F. L. Beyer, G. L. Fiore, S. J. Rowan and C. Weder, Nature, 2011, 472, 334-337.
7 V. Marin, E. Holder, R. Hoogenboom and U. S. Schubert, Chem. Soc. Rev., 2007, 36, 618-635.

8 F. Han, M. Higuchi and D. Kurth, J. Am. Chem. Soc., 2008, 130, 2073-2081.

9 Y. Chujo, K. Sada and T. Saegusa, Macromolecules, 1993, 26, 6315-6319.

10 A. Kokil, I. Shiyanovskaya, K. Singer and C. Weder, J. Am. Chem. Soc., 2002, 124, 9978-9979.

11 M. Ruben, U. Ziener, J. M. Lehn, V. Ksenofontov, P. Gutlich and G. B. M. Vaugghan, Chem. - Eur. J., 2005, 11, 94-100.

12 G. Schwarz, Y. Bodenthin, Z. Tomkowicz, W. Haase, T. Geue, J. Kohlbrecher, U. Pietsch and D. G. Kurth, J. Am. Chem. Soc., 2010, 133, 547-558.

13 D. H. Leung, D. Fiedler, R. G. Bergman and K. N. Raymond, Angew. Chem., Int. Ed., 2004, 43, 963-984.

14 J. Brassinne, C. A. Fustin and J. F. Gohy, J. Inorg. Organomet. Polym., 2013, 23, 24-40.

15 J. B. Beck and S. J. Rowan, J. Am. Chem. Soc., 2003, 125, 13922-13923.

16 J. R. Kumpfer, J. J. Wie, J. P. Swanson, F. L. Beyer, M. E. Mackay and S. J. Rowan, Macromolecules, 2012, 45, 473-480.

17 W. Weng, Z. Li, A. M. Jamieson and S. J. Rowan, Macromolecules, 2009, 42, 236-246.

18 W. C. Yount, D. M. Loveless and S. L. Craig, Angew. Chem., Int. Ed., 2005, 44, 2746-2748.

19 W. C. Yount, D. M. Loveless and S. L. Craig, J. Am. Chem. Soc., 2005, 127, 14488-14496.

20 W. C. Yount, D. M. Loveless and S. L. Craig, J. Am. Chem. Soc., 2003, 125, 15302-15303.

21 C. Mugemana, A. Joset, P. Guillet, M. S. Appavou, N. de Souza, C. A. Fustin, B. Leyh and J. F. Gohy, Macromol. Chem. Phys., 2013, 214, 1699-1709.

22 J. Brassinne, C. Mugemana, P. Guillet, O. Bertrant, D. Auhl, C. Bailly, C. A. Fustin and J. F. Gohy, Soft Matter, 2012, 8, 4499-4506.

23 J. Brassinne, F. Zhuge, C. A. Fustin and J. F. Gohy, Gels, 2015, 1, 235-255.

24 F. D. Jochum, J. Brassinne, C. A. Fustin and J. F. Gohy, Soft Matter, 2013, 9, 2314-2320.

25 J. Brassinne, J. P. Bourgeois, C. A. Fustin and J. F. Gohy, Soft Matter, 2014, 10, 3086-3092.

26 J. Brassinne, A. M. Stevens, E. van Ruymbeke, J. F. Gohy and C. A. Fustin, Macromolecules, 2013, 46, 9134-9143.

27 J. Brassinne, J. F. Gohy and C. A. Fustin, Macromolecules, 2014, 47, 4514-4524.

28 S. J. Buwalda, P. J. Dijkstra and J. Feijen, J. Polym. Sci., Part A: Polym. Chem., 2012, 50, 1783-1791.

29 S. Piogé, C. A. Fustin and J. G. Gohy, Macromol. Rapid Commun., 2012, 33, 534-539.

30 G. Riess, Prog. Polym. Sci., 2003, 28, 1107-1170.

31 I. Astafieva, K. Khougaz and A. Eisenberg, Macromolecules, 1995, 28, 7127-7131.

32 J. Van Stam, S. Creutz, F. C. De Schryver and R. Jérome, Macromolecules, 2000, 33, 6388-6395. 
33 Q. T. Pham, W. B. Russel, J. C. Thibeault and W. Lau, Macromolecules, 1999, 32, 5139-5146.

34 J. F. Berret, D. Calvet and A. Collet, Curr. Opin. Colloid Interface Sci., 2003, 8, 296-306.

35 F. Renou, T. Nicolai, E. Nicol and L. Benyahia, Langmuir, 2009, 25, 515-521.

36 T. Nicolai, O. Colombani and C. Chassenieux, Soft Matter, 2010, 6, 3111-3118.

37 M. T. Popescu, I. Athanasoulias, C. Tsitsilianis, N. A. Hadjiantoniou and C. S. Patrickios, Soft Matter, 2010, 6, 5417-5424.

38 R. Zana, C. Marques and A. Johner, Adv. Colloid Interface Sci., 2006, 123-126, 345-351.

39 Z. M. O. Rzaev, S. Dincer and E. Piskin, Prog. Polym. Sci., 2007, 32, 534-595.

40 Y. Xia, X. Yin, N. A. D. Burke and H. D. H. Stover, Macromolecules, 2005, 38, 5937-5943.

41 P. Kujawa, F. Segui, S. Shaban, C. Diab, Y. Okada, F. Tanaka and F. M. Winnik, Macromolecules, 2006, 39, 341-348.

42 R. Plummer, D. J. T. Hill and A. K. Whittaker, Macromolecules, 2006, 39, 8379-8388.

43 H. T. Ho, M. E. Levere, S. Pascual, V. Montembault, N. Casse, A. Caruso and L. Fontaine, Polym. Chem., 2013, 4, 675-685.

44 M. E. Levere, H. T. Ho, S. Pascual and L. Fontaine, Polym. Chem., 2011, 2, 2878-2887.
45 J. Chiefari, Y. K. Chong, F. Ercole, J. Krstina, J. Jeffery, T. P. T. Le, R. T. A. Mayadunne, G. F. Meijs, C. L. Moad, E. Rizzardo and S. H. Thang, Macromolecules, 1998, 31, 5559-5562.

46 Handbook of RAFT Polymerization, ed. C. Barner-Kowollik, Wiley-VCH, Weinheim, 2008.

47 Z. An, Q. Shi, W. Tang, C. K. Tsung, C. J. Hawker and G. D. Stucky, J. Am. Chem. Soc., 2007, 129, 14493-14499.

48 T. H. Ho, M. E. Levere, D. Fournier, V. Montembault, S. Pascual and L. Fontaine, Aust. J. Chem., 2012, 65, 970977.

49 R. H. Holyer, C. D. Hubbard, S. F. A. Kettle and R. G. Wilkings, Inorg. Chem., 1966, 5, 622-625.

50 F. Peng, G. Li, X. Liu, S. Wu and Z. Tong, J. Am. Chem. Soc., 2008, 130, 16166-16167.

51 H. Hofmeier and U. S. Schubert, Macromol. Chem. Phys., 2003, 204, 1391-1397.

52 H. G. Schild, Prog. Polym. Sci., 1992, 17, 163-249.

53 H. Cheng, L. Shen and C. Wu, Macromolecules, 2006, 39, 2325-2329.

54 M. Chiper, D. Fournier, R. Hoogenboom and U. S. Schubert, Macromol. Rapid Commun., 2008, 29, 16401647.

55 C. Chassenieux, T. Nicolai and L. Benyahia, Curr. Opin. Colloid Interface Sci., 2011, 16, 18-26.

56 G. Marrucci, S. Bhargava and S. L. Cooper, Macromolecules, 1993, 26, 6483-6488. 